\title{
Detection of gastroesophageal reflux in children with cerebral palsy using combined multichannel intraluminal impedance- ph procedure
}

\author{
Gönül Çaltepe ${ }^{1}$, Özlem Yüce ${ }^{1}$, Atakan Combaํ․ Hamit Özyürek ${ }^{2}$, Ayhan Gazi Kalayci ${ }^{1}$ \\ Haydar Ali Taşdemir ${ }^{2}$ \\ Units of ${ }^{1}$ Pediatric Gastroenterology, Hepatology and Nutrition and ${ }^{2}$ Pediatric Neurology, Ondokuz Mayns University \\ Faculty of Medicine, Samsun, Turkey. E-mail: caltepeg@gmail.com,gdinler@omu.edu.tr \\ Received: 18th October 2016, Revised: 10th November 2016, Accepted: 6th January 2017
}

\begin{abstract}
SUMMARY: Çaltepe G, Yüce Ö, Comba A, Özyürek H, Kalaycı AG, Taşdemir HA. Detection of gastroesophageal reflux in children with cerebral palsy using combined multichannel intraluminal impedance- $\mathrm{pH}$ procedure. Turk J Pediatr 2016; 58: 524-531.

Gastroesophageal reflux (GER) is a very common condition in children with neurological impairment and this can influence nutritional and respiratory outcomes. The aim of this study was to investigate the presence of GER in children with cerebral palsy $(\mathrm{CP})$ using multiple intraluminal impedance (MII)-pH monitoring. The use of combined MII-pH allows for the detection of both acid and non-acid reflux episodes. A total of $29 \mathrm{CP}$ patients with symptoms suggesting GER, aged 2 to 10 years old, underwent 24-hour combined MII-pH monitoring. There were a total of 3899 reflux episodes, of which $29 \%$ were acid, $60 \%$ were weakly acid and $11 \%$ were alkaline. The number of non-acid reflux episodes was statistically significantly greater $(p<0.01)$. These findings confirm that GER disease is seen frequently in children with cerebral palsy and most of the reflux episodes are not acidic. Non-acid reflux can also influence the morbidity in patients with cerebral palsy. It can be concluded that $70 \%$ of the reflux episodes would not have been recognized by $\mathrm{pH}$ measurement alone.
\end{abstract}

Key words: cerebral palsy, children, gastroesophageal reflux, multiple intraluminal impedance, non-acid reflux.

Gastroesophageal reflux (GER) is a common problem in neurologically disabled children and when it causes symptoms and/or complications it is known as gastroesophageal reflux disease (GERD). Impairment of the brain may result in significant dysfunction in the gastrointestinal tract $^{1}$. Oro-motor disabilities, swallowing incoordination, abnormal esophageal motility and GER are the most common problems of these children ${ }^{1-3}$. Approximately $75-90 \%$ of children with cerebral palsy (CP) have been reported to have GER in different studies $^{2-4}$. Many factors may be involved in the etiopathogenesis of GER in CP patients, including motility disorders, seizures, supine position, and increased intra-abdominal pressure secondary to spasticity and scoliosis. Recurrent episodes of GER can lead to overt or silent aspiration, vomiting, spillage, food aversion, prolonged feeding times and may result in a significant reduction in nutrient and energy intake ${ }^{3}$.

One of the best methods for the diagnosis of GER is 24-hour esophageal pH monitoring5. This method detects reflux in the $\mathrm{pH}$ below 4, but GER episodes of weak acidity are not detected with this method. Neonates, infants and neurologically impaired children tend to have weak acid reflux because of the frequent feeding and neutralization of the gastric content following milk or formula ${ }^{6-8}$. Therefore, it is not possible to detect all reflux episodes with $\mathrm{pH}$ monitoring. Multichannel intraluminal impedance (MII) is a $\mathrm{pH}$ independent method to investigate the bolus transport in the esophagus, either retrograde 
from the stomach or antegrade toward the stomach. The intraluminal catheter also has a $\mathrm{pH}$ sensor. Thus, a combined esophageal multichannel intraluminal impedance-pH (MII$\mathrm{pH})$ technique may detect all GER episodes and classify GER episodes according to their $\mathrm{pH}$ value and proximal extension ${ }^{9-14}$

Early suspicion and the management of GERD has an important impact on the respiratory and nutritional status of children with CP. It is also known that non-acid reflux is as important as acid reflux in these disabled children. Therefore, the evaluation of reflux with combined MII-pH monitoring can allow not only acidic but weak acid and alkaline reflux episodes to be assessed.

The aim of this study was to evaluate GER in children with $\mathrm{CP}$ and to evaluate the reflux episodes in terms of acid and non-acid nature.

\section{Material and Methods}

This was a prospective study of children with cerebral palsy aged 2 to 18 years who were referred to the Pediatric Gastroenterology Hepatology and Nutrition clinic for evaluation of GER with symptoms included regurgitation, vomiting, rumination, feeding difficulties and recurrent pulmonary problems. Exclusion criteria were any other chronic cardiac, pulmonary, or metabolic diseases, sepsis, the need for any ventilator support at the time of the study and lack of parental consent. A total of 30 patients who met the criteria were enrolled in the study. The study protocol included a detailed medical history and physical examination, especially in terms of motor and feeding abilities. The patient motor functions were classified according to the Gross Motor Function Classification System (GMFCS) ${ }^{15,16}$. Anthropometric measurements were taken including body weight and height. As height may not be correctly measured in children with skeletal contractures, scoliosis or an inability to stand, weight measurements were taken into account. Patients were defined as having malnutrition if the weight for age percentile was $<10$, according to growth charts for children with $\mathrm{CP}^{15}$.

All patients underwent $24 \mathrm{hr}$ multichannel intraluminal impedance (MII)-pH monitoring using an ambulatory system (Ohmega, MMS, Enschede, The Netherlands). This system consists of a portable data logger (MMS Investigation and Diagnostic Software $\left.{ }^{\circledR}\right)$ and a disposable catheter which contains one $\mathrm{pH}$ electrode and seven impedance electrodes (Unisensor, Attikon, Switzerland). Before recording, the $\mathrm{pH}$ electrode was calibrated in special buffer solutions at $\mathrm{pH}$ values of 1 and 7. The catheter was placed transnasally and the $\mathrm{pH}$ sensor was situated 2-3 cm above the lower esophageal sphincter (LES), as calculated by the Strobel formula ${ }^{17}(0.252 \mathrm{x}$ body length [cm] $+5)$, and was then confirmed by X-ray. Patients were asked not to use anti-reflux medications for at least five days before the procedure. All the children were admitted to our in-patient unit on the day of the procedure and discharged on the following day. During the monitoring period, patients were permitted to continue

Table I. Characteristics of the Patients with Cerebral Palsy

\begin{tabular}{lc}
\hline Patients & $\mathrm{n}=29$ \\
\hline Age, years, mean \pm SD (median, range) & $4.0 \pm 2.3$ years $(3.5 ; 2-10$ years) \\
Male/Female ratio (\%) & $13 / 16(44.8 / 55.2)$ \\
Types of cerebral palsy, n (\%) & $15(51.7 \%)$ \\
Spastic & $10(34.5 \%)$ \\
Generalized hypotonic & $4(13.8 \%)$ \\
Mixed & $1(3.5 \%)$ \\
Gross motor function classification (GMFC) & $28(96.5 \%)$ \\
Class IV & $7(\%)$ \\
Class V & \\
Tube feeding & $17(58.6 \%)$ \\
Weight for age percentile* & $11(37.9 \%)$ \\
$<10 \mathrm{p}$ & $1(3.5 \%)$ \\
$10-50 \mathrm{p}$ & \\
$>50 \mathrm{p}$ &
\end{tabular}

*According the growth charts for children with $\mathrm{CP}$ 
Table II. Symptoms and Presenting Features of the Patients*

\begin{tabular}{lcc}
\hline Symptoms & Number of patients $(\mathrm{n}=29)$ & $\%$ \\
\hline Gastrointestinal & 19 & 65.5 \\
Feeding difficulties & 19 & 65.5 \\
Constipation & 15 & 51.7 \\
Vomiting & 12 & 41.4 \\
Inability to swallow & 7 & 24.1 \\
Rumination & 4 & 13.8 \\
Hematemesis & 3 & 10.3 \\
Pulmonary & 17 & 58.6 \\
Chronic cough & 17 & 58.6 \\
Wheezing & 13 & 44.8 \\
Recurrent pneumonia & 10 & 34.5 \\
\hline
\end{tabular}

*Patients were presented with more than one symptoms.

daily activities and oral or enteral intake of anything except acidic foods. Caregivers were asked to press the labeled buttons and complete a diary recording at the same time for the meals and body position. The MII-pH data were analyzed using MMS software and were manually reviewed by the same investigator (G.Ç.). Written informed consent was obtained from the parents or legal guardians of all the study participants. The study was approved by the Ethics Committee of Ondokuz Mayis University Hospital.

\section{Definitions ${ }^{5,10}$}

$\mathrm{pH}$ reflux index (RI); percentage of time with esophageal $\mathrm{pH}<4$.

Reflux index $>4 \%$ was accepted as a positive test result for $\mathrm{pH}$ monitoring

MII reflux event (MIIe); decrease in impedance to $<50 \%$ of the baseline value in at least two channels with upward direction.

Acidic MIIe; episode detected by MII with $\mathrm{pH}<4$.

Weakly acidic MIIe; episode detected by MII with $\mathrm{pH}$ of $4-7$.

Alkaline MIIe; episode detected by MII with $\mathrm{pH}>7$

A total of $>50$ reflux events in 24 hours was accepted as a positive test result for MII monitoring.

\section{Statistical analysis}

Statistical analysis was performed using SPSS version 20.0. Data were expressed as mean \pm standard deviation (SD), as median (min-max) and as frequency (n) and percentage (\%). The Mann-Whitney $U$ test was used to compare variables between two independent groups and the non-parametric Wilcoxon Signed Ranks test was applied to two dependent groups. A value of $\mathrm{p}<0.05$ was considered statistically significant.

\section{Results}

A total of 30 children were enrolled in the study. One patient was excluded due to technical problems in MII-pH tracings. Sufficient data was obtained from 29 patients with a mean age of $4.0 \pm 2.3$ years (median: 3.5 years; range $2-10$ years). The patients comprised $16(55.2 \%)$ females and $13(44.8 \%)$ males. There were $15(51.7 \%)$ spastic, $10(34.5 \%)$ generalized hypotonic and 4 (13.8\%) mixed type of $\mathrm{CP}$ patients. All the patients had severe neurological deficiency of class IV-V according to the CMFCS. On presentation, 7 patients were already fed by tube (Table I).

According to the growth charts for children with CP, the bodyweight of 17 (58.6\%) of the included patients were $<10^{\text {th }}$ percentile, 4 of whom were tube-fed patients. Nearly all $(96.5 \%)$ the patients were $<50^{\text {th }}$ percentile.

The patients presented with a wide range of symptoms, mainly classified as gastrointestinal 
Table III. Mean Values of the $\mathrm{pH}$ Measurements

\begin{tabular}{lc}
\hline Parameters & Mean \pm SD (median; range) \\
\hline Reflux index (RI) (\%) & $16.0 \pm 15.2(10 ; 2.3-48.3)$ \\
Number of reflux events & $62.4 \pm 64.2(42 ; 3-324)$ \\
Number of reflux events lasting $>5$ min & $10.2 \pm 13.3(5 ; 1-47)$ \\
Longest reflux event $(\mathrm{min})$ & $28.8 \pm 20.7(25.9 ; 5.7-68.8)$ \\
Lower pH ever reaching & $1.1 \pm 0.7(1.1 ; 0-2.7)$ \\
\hline
\end{tabular}

Table IV. Comparison of Multichannel Intraluminal Impedance and $\mathrm{pH}$ Monitoring

\begin{tabular}{cccc}
\hline & $\mathrm{pH}$ monitoring positive & $\mathrm{pH}$ monitoring negative & Total \\
\hline MII monitoring positive & 20 & 5 & 25 \\
MII monitoring negative & 2 & 2 & 4 \\
Total & 22 & 7 & 29 \\
\hline
\end{tabular}

Kappa $=0.228(\mathrm{p}=0.193,95 \% \mathrm{CI}: 0.000-0.630)$

and pulmonary symptoms (Table II). A total of 19 patients presented with mainly gastrointestinal symptoms, and 17 with pulmonary symptoms (7 in both groups had both kinds of symptoms).

A total of 674.6 hours (mean $23.3 \mathrm{~h} /$ patient, range 19.2-25.4 hours) of tracings were analyzed during the MII-pH monitoring. In the analysis of the $\mathrm{pH}$ recordings, 1810 episodes were identified as reflux events. The mean number of reflux events was $62.4 \pm 64.2$ and the mean RI was $16.0 \% \pm 15.2 \%$. Twenty two out of 29 patients $(75.8 \%)$ had positive test results according to reflux index. The mean values of the $\mathrm{pH}$ measurements are shown in Table III.

There were a total of 3899 reflux episodes during the study according to the MII-pH monitoring, 25 patients $(86.2 \%)$ had positive test results. The comparisons of MII and $\mathrm{pH}$ monitoring showed that $\mathrm{pH}$ monitoring alone missed 5 patients (Table IV).

In the examination of $\mathrm{pH}$ values of MII-pH monitoring, 1128 (29.0\%) were classified as acid, $2333(60.0 \%)$ as weakly acid and 426 $(10.9 \%)$ as alkaline. 682 out of the 1810 refluxes $(37.6 \%)$ detected by $\mathrm{pH}$ monitoring were not detected as acidic reflux with MII$\mathrm{pH}$. This may be due to the shortness of the events or the inability of the reflux to reach the upper channel. The mean numbers of acidic and weakly acidic MII events (MIIe) were 38.9 and 80.4 respectively (Table $\mathrm{V}$ ). The number of weakly acidic reflux events were determined as 2-fold more than acidic reflux and this was statistically significant $(p<0.010)$. When evaluation was made in terms of proximal extension, 1879 of 3899 MIIe (48.2\%) were found to reach the most proximal channel $\mathrm{Z1}$.

In respect of nutritional status, there were no significant differences between patients with and without malnutrition in terms of MII-pH parameters (Table VI).When patients with and without respiratory symptoms were compared, no significant differences were determined in MII-pH parameters (Table VII). Patients were grouped as spastic $(n=15)$, generalized hypotonic $(\mathrm{n}=10)$ and mixed $(\mathrm{n}=4)$ according to the type of CP. There were no significant differences between these groups in terms of MII-pH parameters (Data is not shown).

\section{Discussion}

Gastrointestinal problems are well known to be a frequent occurrence in children with CP. Studies have shown that feeding difficulties, chronic pulmonary aspiration, constipation, malnutrition and GER are the major problems in children with $\mathrm{CP}^{1,2,18,19}$. Many studies have indicated that patients with CP, particularly in its severe form, are at high risk of developing GERD 2,20,21, which is probably because of the generalized dysmotility and the altered mechanism of the lower esophageal sphincter. A high frequency of GER, up to $90 \%$, depending on the diagnostic method, has been reported in neurologically impaired children in different 
Table V. Mean Values of the MII-pH Measurements.

\begin{tabular}{lc}
\hline Parameters & Mean \pm SD (median; range) \\
\hline Total number of MIIe & $134.5 \pm 122.9(109 ; 20-561)$ \\
Number of acidic MIIe & $38.9 \pm 61.7(17 ; 1-311)^{*}$ \\
Number of weakly acidic MIIe & $80.4 \pm 72.8(53 ; 9-303)^{*}$ \\
Number of alkaline MIIe & $14.7 \pm 46.3(1 ; 0-242)$ \\
Total number of MIIe reaching Z1 channel & $79.8 \pm 77.0(42 ; 2-289)$ \\
Acidic MIIe reaching Z1 channel & $26.1 \pm 38.4(13 ; 1-151)$ \\
Weakly acidic MIIe reaching Z1 channel & $38.4 \pm 45.8(15 ; 1-162)$ \\
Alkaline MIIe reaching Z1 channel & $15.4 \pm 34.6(15 ; 1-119)$ \\
\hline
\end{tabular}

*p $<0.010$

MIIe; Multichannel Intraluminal Impedance event

studies $^{2,18,22}$. Many different methods such as nuclear scintigraphy, barium contrast graphs, endoscopy and biopsy, esophageal pH-metry and impedance have been used to diagnose GER. There are advantages and disadvantages of each method, and the facilities and experience of the center are also important when selecting the test to be used. Esophageal pH-monitoring is one of the most convenient methods but it only recognizes acidic episodes of reflux ${ }^{12,13,23,24}$. A significant proportion of reflux episodes are known to be non-acidic, especially in infants ${ }^{23-27}$. As emphasized in the most recent guidelines, combined multiple intraluminal impedance and $\mathrm{pH}$ monitoring (MII-pH) is the most reliable method to evaluate GER ${ }^{5,10}$.
MII-pH recognizes all reflux episodes including non-acidic ones. This is also important in neurologically impaired children who are frequently fed liquid meals 8,22 .

Multiple intraluminal impedance technique is based on the ionic concentrations of the luminal contents ${ }^{6,10}$. Bolus with no ionic contents, such as gas (air), results in a rise in impedance but relatively high ionic contents such as refluxate results in a drop in impedance. A bolus-liquid reflux is defined as a retrograde drop in impedance of at least $50 \%$ of the baseline level. The use of MII technique allows the analysis of movement direction and proximal extent of the bolus. When a $\mathrm{pH}$ sensor is added to the MII catheter, it can also discriminate both

Table VI. MII-pH Comparison Between Patients with and Without Malnutrition

\begin{tabular}{lccc}
\hline & Group I $(\mathrm{n}=17)$ & Group II $(\mathrm{n}=12)$ & $P$ \\
Age (year) & $4.5 \pm 2.7(4 ; 2-10)$ & $4.2 \pm 3.0(3.2 ; 2-10)$ & 0.738 \\
Number of MIIe & $153.1 \pm 154.9(111 ; 60-561)$ & $170.1 \pm 139.1(109 ; 20-388)$ & 0.121 \\
Acidic & $34.8 \pm 27.8(21 ; 1-89)$ & $81.3 \pm 114.5(44 ; 11-311)$ & 0.097 \\
Weakly acidic & $90.2 \pm 84.1(62 ; 36-303)$ & $78.4 \pm 70.3(62 ; 9-209)$ & 0.535 \\
Alkaline & $28.5 \pm 80.0(2 ; 0-242)$ & $10.2 \pm 10.5(8 ; 0-23)$ & 0.053 \\
MIIe reaching Z1 channel & $107.1 \pm 84.2(70 ; 2-277)$ & $89.1 \pm 101.0(50 ; 14-289)$ & 0.236 \\
Acidic & $26.1 \pm 38.6(123 ; 1-126)$ & $41.5 \pm 54.4(22 ; 11-151)$ & 0.687 \\
Weakly acidic & $57.0 \pm 59.8(42 ; 6-162)$ & $45.6 \pm 48.4(32 ; 1-136)$ & 0.182 \\
Alkaline & $24.1 \pm 43.3(1 ; 1-119)$ & $2.2 \pm 2.3(1 ; 1-7)$ & 0.112 \\
Reflux index (RI) $(\%)$ & $16.7 \pm 14.5(12 ; 2-48)$ & $13.6 \pm 16.4(6 ; 2-45)$ & 0.740 \\
Reflux events lasting $>5$ min & $9.0 \pm 9.3(6 ; 1-30)$ & $11.3 \pm 17.9(3 ; 1-47)$ & 0.982 \\
Longest reflux event $(\min )$ & $38.6 \pm 22.1(39 ; 5-69)$ & $19.0 \pm 14.5(13 ; 7-45)$ & 0.150 \\
\hline
\end{tabular}

Data is expressed as mean \pm SD (median; range)

Group I: Weight for age percentile $<10$ P, Group II: Weight for age percentile $\geq 10$ P, according to growth charts for CP patients ${ }^{15}$

MIIe; Multichannel Intraluminal Impedance event 
Table VII. MII-pH Comparison Between Patients With and Without Pulmonary Symptoms

\begin{tabular}{lccc}
\hline & $\begin{array}{c}\text { Patients with pulmonary } \\
\text { symptoms }(\mathrm{n}=17)\end{array}$ & $\begin{array}{c}\text { Patients without pulmonary } \\
\text { symptoms }(\mathrm{n}=12)\end{array}$ & $\mathrm{P}$ \\
\hline Age (year) & $3.4 \pm 2.0(2.5 ; 1-9)$ & $5.2 \pm 3.0(5.5 ; 2-10)$ & 0.080 \\
Number of MIIe & $109.8 \pm 83.3(110 ; 21-291)$ & $169.4 \pm 161.5(103 ; 20-561)$ & 0.647 \\
Acidic & $33.9 \pm 39.6(21 ; 1-151)$ & $45.9 \pm 85.6(16 ; 1-311)$ & 0.948 \\
Weakly acidic & $71.2 \pm 54.9(53 ; 10-209)$ & $93.4 \pm 93.8(54 ; 9-303)$ & 1.000 \\
Alkaline & $3.8 \pm 7.7(0 ; 0-23)$ & $30.0 \pm 70.2(5 ; 0-242)$ & 0.073 \\
MIIe reaching Z1 channel & $44.8 \pm 37.8(41 ; 2-126)$ & $105.6 \pm 104.3(72 ; 7-289)$ & 0.162 \\
Acidic & $17.3 \pm 18.0(13 ; 1-69)$ & $38.9 \pm 53.7(16 ; 4-151)$ & 0.483 \\
Weakly acidic & $24.8 \pm 22.0(14 ; 1-69)$ & $58.0 \pm 63.3(25 ; 3-162)$ & 0.342 \\
Alkaline & $12.0 \pm 26.6(3.5 ; 1-78)$ & $19.2 \pm 44.0(2 ; 1-119)$ & 0.955 \\
Reflux index (RI) (\%) & $14.30 \pm 12.3(11 ; 2-48)$ & $12.4 \pm 14.2(6 ; 2-45)$ & 0.347 \\
\hline
\end{tabular}

acid and non-acid reflux $6,10,11$. In the current study, a total of 3899 reflux events were detected by MII-pH, of which only $29 \%$ were acidic. Impedance probes identified more reflux episodes than the $\mathrm{pH}$ probes (3899 vs 1810). Thus, the mean number of weakly acidic reflux episodes were determined at double the rate of the mean number of acidic reflux episodes, which was statistically significant $(p<0.01)$. In a recent study, Liu et al. ${ }^{26}$ showed that MII-pH monitoring detected a 3-fold increase in nonacid reflux episodes in comparison with acid reflux episodes. The impact of non-acid reflux is very important in a study population such as the one in the current study. Non-acid reflux is known to be mostly seen in infants because of the frequent feeding and the buffer effect of the milk. There may be a similar effect in neurologically disabled children, because they are fed with liquid formulas and need much more time to finish each meal. Therefore both acid and non-acid reflux events may precede symptoms in children with CP.

The results of the current study indicate that malnutrition is a very common condition in children with $\mathrm{CP}$, which is in agreement with previous studies ${ }^{1,2}$. It is thought to occur not because of increased energy expenditure, but because of inadequate energy intake ${ }^{18,28}$. Conditions such as oro-motor dysfunction, chewing and swallowing difficulties and GER cause prolonged mealtimes and inadequate nutrition. Severely neurologically handicapped children in particular are at great risk of developing malnutrition ${ }^{1,28-30}$. In a recent study, patients with CP had significantly lower anthropometric measurements than a control group and the difference was particularly evident in patients with a higher grade of motor disability $^{20}$. In the current study, all the patients had high degree neurological disabilities of grade IV-V according to the GMFC. In $58.6 \%$ of the patients, bodyweight was $<10^{\text {th }}$ percentile according to the CP special growth charts. This high percentage of malnutrition was not a surprise because they were severely disabled patients, being fed with semi-liquid or puree type foods and almost one quarter were already on tube feeding. To evaluate if there was any impact of GER on malnutrition, children with and without malnutrition were compared. The mean values of the MII-pH monitoring parameters did not reveal any significant difference, including the number of acid and non-acid reflux episodes. Even though no significant difference was determined in the effect of acid and non-acid reflux on nutrition, it was observed that reflux episodes reaching the proximal channel constituted almost half of the total reflux episodes. It may be assumed that high GER reaching the proximal channel is particularly meaningful in children with pulmonary symptoms, suggesting the possibility of micro aspiration of gastric contents into the bronchial tree ${ }^{31}$. The $\mathrm{pH}$ value of reflux episodes is important especially in infants ${ }^{9}$. In previous studies, a stronger association has been found between non-acid reflux episodes and respiratory symptoms in children with chronic respiratory disease ${ }^{32,33}$. In a recent study, the authors observed a higher prevalence of weakly acid reflux in infancy 
in otherwise healthy children with a chronic unexplained cough ${ }^{34}$. To make an evaluation from this perspective, children with and without respiratory symptoms were compared but no significant difference was determined in terms of acid, non-acid reflux and proximal extension of the reflux.

In conclusion, GER is frequently seen in children with CP and it causes gastrointestinal and pulmonary morbidity. The great majority of reflux events are non-acidic. The results of this study confirms that non-acid reflux episodes are seen much more than acid reflux in children with $\mathrm{CP}$ and MII-pH monitoring is more effective than $\mathrm{pH}$ alone studies in detecting all reflux events.

\section{REFERENCES}

1. Chong SK. Gastrointestinal problems in the handicapped child. Curr Opin Pediatr 2001; 13: 441-446.

2. Del Giudice E, Staiano A, Capano G, et al. Gastrointestinal manifestations in children with cerebral palsy. Brain Dev 1999; 21: 307-311.

3. Penagini F, Mameli C, Fabiano V, Brunetti D, Dilillo D, Zuccotti GV. Dietary Intakes and Nutritional Issues in Neurologically Impaired Children. Nutrients 2015; 7: $9400-9415$.

4. Sullivan PB. Gastrointestinal disorders in children with neurodevelopmental disabilities. Dev Disabil Res Rev 2008; 14: 128-136.

5. Vandenplas Y, Rudolph CD, DiLorenzo C, et al. Pediatric gastroesophageal reflux clinical practice guidelines: joint recommendations of the North American Society for Pediatric Gastroenterology, Hepatology, and Nutrition (NASPGHAN) and the European Society for Pediatric Gastroenterology, Hepatology, and Nutrition (ESPGHAN). J Pediatr Gastroenterol Nutr 2009; 49: 498-547.

6. vanWijk MP, Benninga MA, Omari TI. Role of the multichannel intraluminal impedance technique in infants and children. J Pediatr Gastroenterol Nutr 2009; 48: $2-12$.

7. Hojsak I, Ivkovic L, Trbojevic T, et al. The role of combined 24-h multichannel intraluminal impedance$\mathrm{pH}$ monitoring in the evaluation of children with gastrointestinal symptoms suggesting gastro-esophageal reflux disease. Neurogastroenterol Motil 2016; 28 : 1488-1493.

8. Del Buono R, Wenzl TG, Rawat D, Thomson M. Acid and nonacid gastro-oesophageal reflux in neurologically impaired children: investigation with the multiple intraluminal impedance procedure. J Pediatr Gastroenterol Nutr 2006; 43: 331-335.

9. Vandenplas Y, Salvatore S, Vieira MC, Hauser B. Will esophageal impedance replace $\mathrm{pH}$ monitoring? Pediatrics 2007; 119: 118-122.
10. Wenzl TG, Benninga MA, Loots CM, Salvatore $S$, Vandenplas Y; ESPGHAN EURO-PIG Working Group. Indications, methodology, and interpretation of combined esophageal impedance-pH monitoring in children: ESPGHAN EURO-PIG standard protocol. J Pediatr Gastroenterol Nutr 2012; 55: 230-234.

11. Wenzl TG. Evaluation of gastroesophageal reflux events in children using multichannel intraluminal electrical impedance. Am J Med 2003; 115(Suppl 3A): 161S-165S.

12. Tutuian R, Vela MF, Shay SS, Castell DO. Multichannel intraluminal impedance in esophageal function testing and gastroesophageal reflux monitoring. J Clin Gastroenterol 2003; 37: 206-215.

13. Mattioli G, Pini-Prato A, Gentilino V, et al. Esophageal impedance / $\mathrm{pH}$ monitoring in pediatric patients: preliminary experience with 50 cases. Dig Dis Sci 2006; 51: 2341-2347.

14. Loots CM, van Wijk MP, Blondeau K, et al. Interobserver and intraobserver variability in $\mathrm{pH}$-impedance analysis between 10 experts and automated analysis. J Pediatr 2012; 160: 441-446.

15. Brooks J, Day S, Shavelle R, Strauss D. Low weight, morbidity, and mortality in children with cerebral palsy: new clinical growth charts. Pediatrics 2011; 128: e299-e307.

16. Palisano R, Rosenbaum P, Walter S, Russell D, Wood E, Galuppi B. Development and reliability of a system to classify gross motor function in children with cerebral palsy. Dev Med Child Neurol 1997; 39: 214-223.

17. Strobel CT, Byrne WJ, Ament ME, Euler AR. Correlation of esophageal lengths in children with height: application to the Tuttle test without prior esophageal manometry. J Pediatr 1979; 94: 81-84.

18. Campanozzi A, Capano G, Miele E, et al. Impact of malnutrition on gastrointestinal disorders and gross motor abilities in children with cerebral palsy. Brain Dev 2007; 29: 25-29.

19. Ferluga ED, Sathe NA, Krishnaswami S, Mcpheeters ML. Surgical intervention for feeding and nutrition difficulties in cerebral palsy: a systematic review. Dev Med Child Neurol 2014; 56: 31-43.

20. Tomoum HY, Badawy NB, Hassan NE, Alian KM. Anthropometry and body composition analysis in children with cerebral palsy. Clin Nutr 2010; 29: 477481.

21. Spiroglou K, Xinias I, Karatzas N, Karatza E, Arsos G, Panteliadis C. Gastric emptying in children with cerebral palsy and gastroesophageal reflux. Pediatr Neurol 2004; 31: 177-182.

22. Thomson M, Rao P, Rawat D, Wenzl TG. Percutaneous endoscopic gastrostomy and gastro-oesophageal reflux in neurologically impaired children. World J Gastroenterol 2011; 17: 191-196.

23. Wenzl TG, Moroder C, Trachterna M, et al. Esophageal $\mathrm{pH}$ monitoring and impedance measurement: a comparison of two diagnostic tests for gastroesophageal reflux. J Pediatr Gastroenterol Nutr 2002; 34: 519-523. 
24. Francavilla R, Magista AM, Bucci N, et al. Comparison of esophageal $\mathrm{pH}$ and multichannel intraluminal impedance testing in pediatric patients with suspected gastroesophageal reflux. J Pediatr Gastroenterol Nutr 2010; 50: 154-160.

25. Pilic D, Fröhlich T, Nöh F, et al. Detection of gastroesophageal reflux in children using combined multichannel intraluminal impedance and $\mathrm{pH}$ measurement: data from the German Pediatric Impedance Group. J Pediatr 2011; 158: 650-654.

26. Liu YW, Wu JF, Chen HL, et al. The Correlation Between Endoscopic Reflux Esophagitis and Combined Multichannel Intraluminal Impedance-pH Monitoring in Children. Pediatr Neonatol 2016; 57: 385-389.

27. Lopez-Alonso M, Moya MJ, Cabo JA, et al. Twenty-fourhour esophageal impedance-pH monitoring in healthy preterm neonates: rate and characteristics of acid, weakly acidic, and weakly alkaline gastroesophageal reflux. Pediatrics 2006; 118: e299-e308.

28. Stallings VA, Zemel BS, Davies JC, Cronk CE, Charney EB. Energy expenditure of children and adolescents with severe disabilities: a cerebral palsy model. Am J Clin Nutr 1996; 64: 627-634.
29. Reilly S, Skuse D, Poblete X. Prevalence of feeding problems and oral motor dysfunction in children with cerebral palsy: a community survey. J Pediatr 1996; 129: 877-882.

30. Stallings VA, Cronk CE, Zemel BS, Charney EB. Body composition in children with spastic quadriplegic cerebral palsy. J Pediatr 1995; 126: 833-839.

31. Condino AA, Sondheimer J, Pan Z, Gralla J, Perry D, O'Connor JA. Evaluation of infantile acid and nonacid gastroesophageal reflux using combined $\mathrm{pH}$ monitoring and impedance measurement. J Pediatr Gastroenterol Nutr 2006; 42: 16-21.

32. Rosen R, Nurko S. The importance of multichannel intraluminal impedance in the evaluation of children with persistent respiratory symptoms. Am J Gastroenterol 2004; 99: 2452-2458.

33. Wenzl TG, Schenke S, Peschgens T, Silny J, Heimann G, Skopnik H. Association of apnea and nonacid gastroesophageal reflux in infants: Investigations with the intraluminal impedance technique. Pediatr Pulmonol 2001; 31: 144-149.

34. Ghezzi M, Guida E, Ullmann N. Weakly acidic gastroesophageal refluxes are frequently triggers in young children with chronic cough. Pediatr Pulmonol 2013; 48: 295-302. 